\title{
The Influence of Ageing on Martensite Morphology in Shape Memory CuZnAl Alloys
}

\author{
N. Kayali, S. Özgen and O. Adigüzel \\ Department of Physics, Firat University, 23169 Elaziğ, Turkey
}

\begin{abstract}
The martensitic transformation behaviour, morphology and microstructures in copper-based shape memory alloys are strongly influenced by the post-quench heat treatments and ageing. Martensitic transformation initiates at a critical temperature and grows by the formation of martensite yariants on cooling up to martensite finish temperature. These alloys are metastable at the matrix $\beta$-phase condition, and reversibility of transformation and formation of martensite variants from the matrix are related to the elementary mechanisms. The interfacial motion between martensite variants is also important in shape memory. Vickers hardness shows a trend to increase with holding duration at ageing temperature of $200^{\circ} \mathrm{C}$ for both alloys. Martensite plates have similar morphology in as-quenched and post-quench heat treated specimens, and growth units of two or four plates constitute selfaccommodating systems.
\end{abstract}

\section{INTRODUCTION}

Martensitic transformations are known as first-order phase transitions associated with a shape change in metals and alloys, and occur by a shear-like mechanism called invariant plane strain. The shape memory effect (SME) observed in a series of alloy systems [1-4] is a direct result of thermoelastic martensitic transformation. Shape memory alloys (SMAs) deform by variant-to-variant transformations in case they are stressed in the martensitic condition and the resultant variants transform to the parent phase on heating above the $A_{f}$ temperature, covering the original shape [5].

Copper-based alloys exhibit shape memory in $\beta$-phase region which posses disordered structure A2 type at high temperatures. The $\beta$-phase alloys undergo two ordered structures $\mathrm{B} 2$ or $\mathrm{DO}_{3}$ on quenching and transform to multilayered martensite structures, $9 \mathrm{R}$ and 18R type, respectively, under further cooling to a temperature below $M_{s}$ [6]. In a single crystal of $\beta$ parent phase, 24 martensite variants grouped around six $\{110\}_{\text {bcc }}$ matrix planes which consist of four different variants can be formed at temperatures below $\mathbf{M}_{\mathrm{s}}$, and variants in a group always appear in a so-called self-accommodating martensite morphology. Self-accommodation mechanism is known to operate to minimize total shape change, and the shape change is therefore essential to martensitic transformation [7].

In recent years, many researchers have studied the materials with reversible shape memory property, because of the convenience to design various actuators, shape memory devices, or the necessity of building a thermal engine since these alloys posses the ability to generate spontaneous changes of shape on thermal cycling. Therefore, there exists a lot of literature data on the mechanism and effect of different conditions of the SME in copper-based $\beta$-phase alloys and this subject still is the source of technological interest. This is due to the fact that degradation of the shape memory properties with thermal cycling [5] and the stabilization of martensite transforming above room temperature $[4,6]$, and many discrepancies arise among the results obtained by many researchers and also caused by different interpretations of the results. On the other hand, shape memory $\mathrm{CuZnAl}$ alloys are very sensitive to low and high temperature heat treatments which can strongly alter their transformation temperatures, martensite morphology and hardness due to the changes in the nature of the layered structures and formation of regions of stable $\alpha$ phase or changes in the configurational degree of martensite $[8,9]$.

In the present study, the reverse transformation temperatures of two shape memory CuZnAl alloys were determined by means of differential scanning calorimeter technique. The changes occurring in the martensite morphology and hardness on ageing in the austenitic condition were also investigated by means of optical microscope observations and Vickers microhardness measurements, respectively. 


\section{EXPERIMENTAL PROCEDURE}

Two shape memory CuZnAl alloys were supplied by Delta Materials Research Ltd., Ipswich, England. These alloys received in the closed-coil form called the shape memory actuator have the originally opencoil form in austenitic condition. These alloys are labeled as Alloy 1 and Alloy 2, and their alloy compositions and electron/atom ratios (e/a) have been given in Table 1 . The specimens for the experiments have been prepared by cutting pieces from these actuators.

Table 1: Chemical compositions and e/a ratios for the alloys.

\begin{tabular}{|c|c|c|c|c|}
\hline \multirow[b]{2}{*}{ Alloy No } & \multicolumn{3}{|c|}{ Composition (in atomic \%) } & \multirow[b]{2}{*}{ e/a ratio } \\
\hline & $\mathrm{Cu}$ & $\mathrm{Zn}$ & $\mathrm{Al}$ & \\
\hline 1 & 67.04 & 23.06 & 9.90 & 1.4286 \\
\hline 2 & 67.88 & 19.62 & 12.50 & 1.4462 \\
\hline
\end{tabular}

For the DSC measurements, disc-shaped specimens of 82 and $68 \mathrm{mg}$ from the alloys 1 and 2 in the received state were prepared in 5 and $3 \mathrm{~mm}$ diameters, respectively. For the reverse transformation temperature measurements, calorimetric experiments were performed in a computer-controlled Shimadzu DSC-50 instrument at a rate of $5^{\circ} \mathrm{C}$ a minute between $20^{\circ} \mathrm{C}$ and $80^{\circ} \mathrm{C}$. $\mathrm{A}_{\mathrm{s}}$ and $\mathrm{A}_{\mathrm{f}}$ temperatures of both alloys were determined by the DSC measurements for first, second and third cycles.

For the metallographic investigations, the specimens have been solution treated in the $\beta$-phase condition $\left(820^{\circ} \mathrm{C}\right.$ for 30 minutes) for homogenization and quenched in iced-brine to retain the $\beta$-phase. These specimens have been aged in the austenitic condition at $200^{\circ} \mathrm{C}$ for up to 8 hours: All specimens were mechanically polished and etched by a solution of $5 \mathrm{~g}$ ferric chloride, $96 \mathrm{ml}$ methanol and $20 \mathrm{ml}$ concentrate $\mathrm{HCl}$. In order to obtain the surface morphology after quenching and ageing in the austenitic condition, metallographic observations were carried out using a Reichert MeF2 optical microscope. Vickers microhardness measurements were performed on the polished specimens under a constant load of $200 \mathrm{~g}$ by using an Ernst Leitz GMBH D-6330 Wetzlar Miniload Hardness Tester instrument.

\section{RESULTS AND DISCUSSION}

In order to determine the crystal structure of two $\mathrm{CuZnAl}$ alloys in the martensitic state, $\mathrm{X}$-ray diffraction profiles were taken from the as-quenched powder specimens. The lattice parameters of Alloy 1 and Alloy 2 have been calculated as follows, respectively;

$$
\begin{aligned}
& a=4.4152 \AA, b=5.3380 \AA, c=38.2066 \AA \text { and } \beta=88.3005^{\circ}, \text { and } \\
& a=4.4674 \AA, b=5.3276 \AA, c=38.2364 \AA \text { and } \beta=88.7742^{\circ}
\end{aligned}
$$

The peaks observed in the X-ray profiles were identified as M18R martensite superlattice reflections and indexed on the monoclinic base. According to these results, the transformations from parent to martensite have been realized as $\mathrm{DO}_{3} \rightarrow 18 \mathrm{R}$. The details related to the $\mathrm{X}$-ray examinations have been given in a previous paper [9].

Martensite $\rightarrow$ austenite transformation temperatures were determined by means of DSC technique for first, second and third cycles. These temperatures are shown on DSC profiles in Figure 1(a and $b$ ) for Alloy 1 and 2, respectively. DSC curves which belong to the first reverse transformation cycle spread over a higher temperature range than the second and third ones (except for first $A_{\mathrm{f}}$ temperature of Alloy 1 , and the reason of this can not be explained). The first endothermic peaks are centered at $53.3^{\circ} \mathrm{C}$ and $42.3^{\circ} \mathrm{C}$ for the samples of Alloy 1 and 2, respectively, while latter peaks are narrower than the formers.

$A_{s}, A_{\max }$ and $A_{f}$ temperatures in the first cycle were measured to be $46.0^{\circ} \mathrm{C}, 53.3^{\circ} \mathrm{C}, 57.3^{\circ} \mathrm{C}$ for alloy 1 and $37.7^{\circ} \mathrm{C}, 42.3^{\circ} \mathrm{C}, 53.3^{\circ} \mathrm{C}$ for Alloy 2. These temperatures are the highest values according to the following cycles (except for $A_{f}$ value of Alloy 1). Some mechanisms for this strong stabilization of martensite after quenching have been proposed in literature: (i) pinning of martensite grain boundaries by quenched-in vacancy or vacancy clusters $[10,11]$. The development of martensite stabilization occurs more rapidly in the presence of vacancies quenched into the martensite from higher temperatures [12]. Boundary pinning is a short range effect and may be responsible for the martensite stabilization [5]. Any heat treatment that reduces the amount of vacancies also reduces the extent of such stabilization, and this interpretation is supported by decreasing of reverse transformation temperatures as seen from Figure 1(a 
and b). (ii) Lowering of the martensite free energy by the reordering process in the martensite, and it is suggested that this process is assisted by the high vacancy concentration $[8,13]$. This mechanism is supported by occurence of high $\Delta \mathrm{d}$ values for some selected X-ray peak pairs such as $12 \overline{2}-202$ and $12 \overline{8}$ 208 in X-ray diffractograms taken from the as-quenched specimens as can be seen in a previous paper [9]. As seen from Figure 1( $a$ and $b$ ), reverse transformation temperatures in second and third cycles return the normal values.

On the other hand, as shown in Figure $1 \mathrm{~b}$ the energy absorbed by the Alloy 2 specimen in first cycle has the highest value of $349.11 \mathrm{~mJ}$ in convenience to the martensite stabilization, and this energy decreases to $285.93 \mathrm{~mJ}$ and $262.14 \mathrm{~mJ}$ in second and third cycles, respectively. On the contrary to these energies, the energy absorbed by Alloy 1 specimen in first cycle as shown in Figure 1a is the lowest value of $15.46 \mathrm{~mJ}$ according to the energies absorbed in second and third cycles realized as $74.38 \mathrm{~mJ}$ and $69.64 \mathrm{~mJ}$, respectively.

Figure 2( $a$ and $b$ ) shows the optical micrographs of Alloy 1 aged at $200^{\circ} \mathrm{C}$ for 30 minutes after quenching and of the Alloy 2 in the quenched case, respectively. As indicated by arrows on these figures, the most characteristic features of the martensite morphologies in $\mathrm{CuZnAl}$ alloys are the prevalence of groups of essentially parallel-sided plates. These types of martensite plates observed in some grains can be grown only in one dimension, i.e., in a direction perpendicular to the parent/martensite interfaces [16].

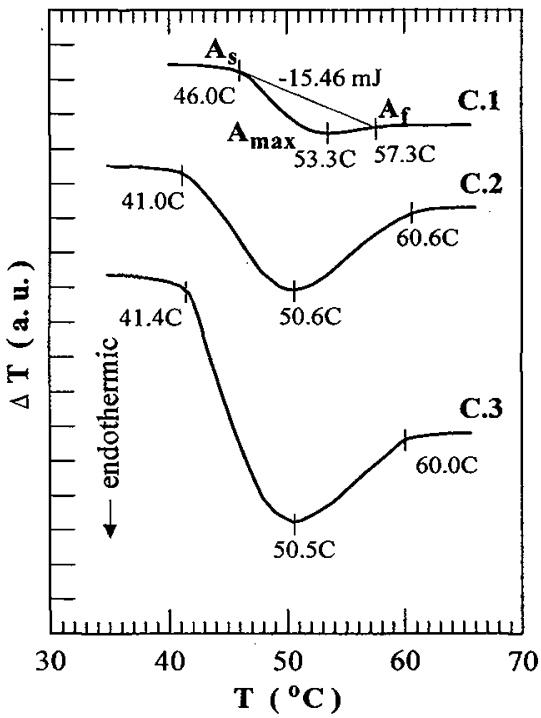

a)

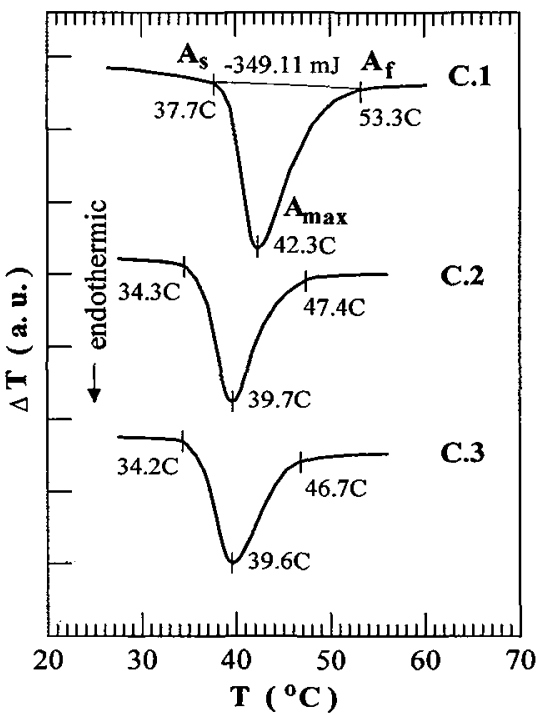

b)

Figure 1: DSC curves with $5^{\circ} \mathrm{C} / \mathrm{min}$ heating rate of a) Alloy 1 and b) Alloy 2 for first, second and third cycles.

It has been predicted that the number of the martensite plates formed in quenched material is directly proportional to the concentration of defects in the $\beta$-phase at the quench time [9]. The large groups of unique orientations within any grain of the parent $\beta$-phase observed in the figure may partially penetrate each other.

The plates observed in the grains in Figure 2(a) and (b) have the different contrast and orientations. It can be seen that these plates show a similar martensite morphology. Therefore, martensite morphologies are not strongly affected by ageing for 30 minutes in the austenitic condition at $200^{\circ} \mathrm{C}$.

The morphology seen in the middle region of Figure 3 is the self-accommodating martensite plates formed in as-quenched Alloy 2 specimen. This structure is also called as a diamond-shaped morphology in $\beta$-phase CuZnAl alloys which produce the martensites which have the long period stacking order structure. In a self-accommodating morphology, six kinds of variant groups are generated from a single crystalline $\beta_{1}$ phase and each of them consists of four different variants, each of which contains four 
cooperating martensite variants which combined produce nearly zero macroscopic shape change $[14,15]$. This enables the materials to deform under low stresses by means of variant coalescence, and this is also an important necessity to provide the SME. Thus, self-accommodating mechanism can also be defined as a mechanism to operate to minimize total shape change. The individual martensite plates are initially either very thin and parallel-sided or grow in broader units of two or four plates. The growth units of two or four plates constitute self-accommodating systems whose junction planes with the matrix are the conventional habit planes whereas their internal junction planes are twin planes of the martensite lattice [9].

Figure 4 shows quite intensive $\alpha$-phase (equilibrium fcc) precipitates formed in Alloy 1 aged at $200^{\circ} \mathrm{C}$ for 8 hours. As pointed out by Shuchuan and coworkers [6], for the fully aged martensite in $\mathrm{CuZnAi}$ alloys, any transformation does not occur during heating up to $120^{\circ} \mathrm{C}$ and precipitates of $\alpha$-phase form as heating above $120^{\circ} \mathrm{C}$. The volume of $\alpha$-phase increases considerably above $240^{\circ} \mathrm{C}$ and the reverse transformation never occurs up to $320^{\circ} \mathrm{C}$ at which martensite is vanished [6]. The transformations occurring during the ageing treatment are the diffusional processes enhanced by an excess concentration of quenched-in vacancies. Due to the change of the chemical composition in the matrix, it has been expected that the precipitation of $\alpha$ or of other phases gives rise to a deterioration in the shape memory capability and decreases of the martensitic transformation temperatures. Due to this decrease, the temperature hysteresis of the reversible SME becomes the broader, which is related to the interaction of martensite interfaces with the precipitates and defects.

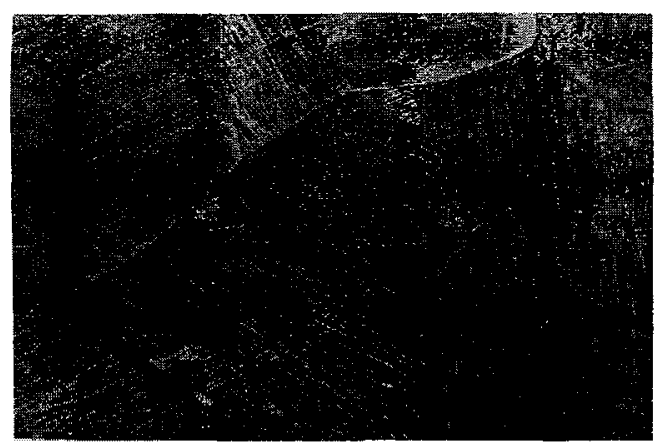

a)

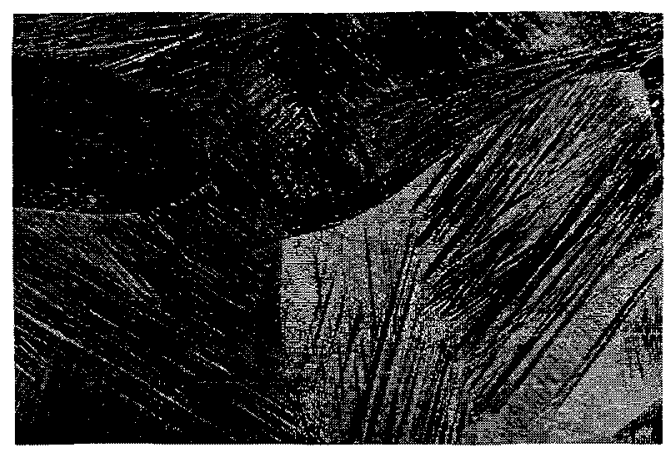

b)

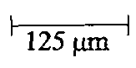

Figure 2: Martensite morphology in a) Alloy 1 aged at $200^{\circ} \mathrm{C}$ for 30 minutes after quenching and b) quenched specimen of Alloy 2.

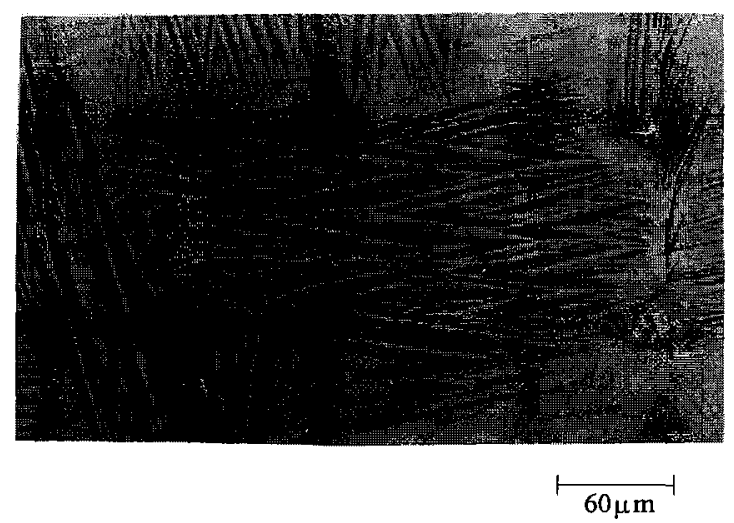

Figure 3: Self-accommodating plate groups formed in a quenched specimen of Alloy 2. 
The $\alpha$-phase precipitates have not been observed in the specimens of Alloy 2 aged up to 8 hours at $200^{\circ} \mathrm{C}$. This can be attributed to the lower content of aluminum of Alloy 2. However, Seguí et al [17] have observed the precipitates of $\gamma$-phase in the aged $\mathrm{CuZnAl}$ alloys with higher content of aluminum. As the formation of precipitates during ageing treatment leads to an increase in resistivity as well as a deterioration in the shape memory capacity. The shape memory life may be approximately predicted by means of the ageing kinetics. Thus, the high shape memory life of $\mathrm{CuZnAl}$ alloys at elevated temperatures can be achieved by increasing the $\mathrm{Al}$ content or lowering the $\mathrm{Zn}$ content.

Figure $5\left(a\right.$ and $b$ ) shows the hardness measurements with the ageing time at $200^{\circ} \mathrm{C}$ for the Alloys 1 and 2, respectively. The four measurements taken after each ageing time can also be seen from these figures, and the hardness values for the same ageing time show a distribution. The reason of this distribution is that the measurements can be taken from different regions of specimens and an amount of deformation up to $5 \%$ can be caused by the deformation of martensite-domains during the loading of the Vickers pyramid [18]. The necessary force to deform the domains is less than the force needed to deform the martensite without this mechanism. The main factor for the increase in hardness after a deformation of more than $5 \%$ is hardening by means of dislocations.

As seen from Figure 5a, the hardness of Alloy 1 gradually rises from $147 \mathrm{~V}_{\mathrm{H}}$ in the quenched state to $275 \mathrm{~V}_{\mathrm{H}}$ after ageing for 8 hours at $200^{\circ} \mathrm{C}$, and according to Figure $5 \mathrm{~b}$, the hardness for Alloy 2 rises from $196 \mathrm{~V}_{\mathrm{H}}$ to $257 \mathrm{~V}_{\mathrm{H}}$ under the same ageing conditions. According to these results, the percentage of increase of the hardness after ageing for 8 hours at $200^{\circ} \mathrm{C}$ are obtained as $88 \%$ and $31 \%$ for Alloy 1 and Alloy 2, respectively. These increases can be attributed to the formation of the equilibrium $\alpha$ phase with a disordered fcc structure, lattice defects and also the deformation of specimen during the loading of Vickers pyramid. Leu and $\mathrm{Hu}$ [19] have observed the $\alpha$ and $\alpha_{1}$ phases in $\mathrm{CuZnAl}$ alloys with lower content of aluminum, and they have also observed the precipitates of $\gamma$ phase in the aged $\mathrm{CuZnAl}$ alloy with higher content of aluminum.

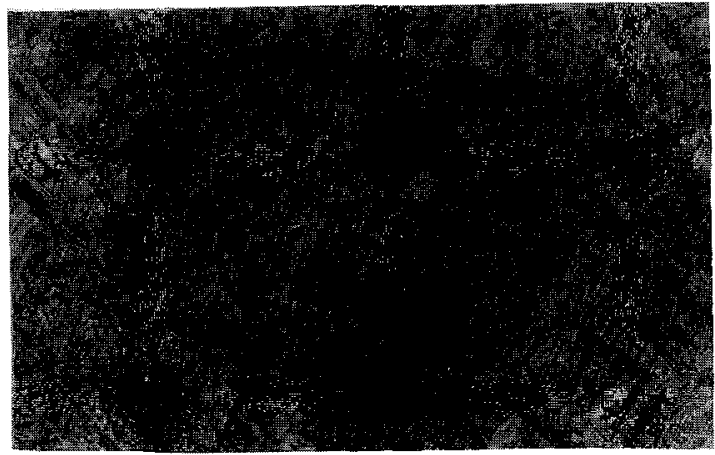

Figure 4: The precipitates of the equilibrium fcc $\alpha$-phase formed in Alloy 1 aged at $200^{\circ} \mathrm{C}$ for 8 hours.

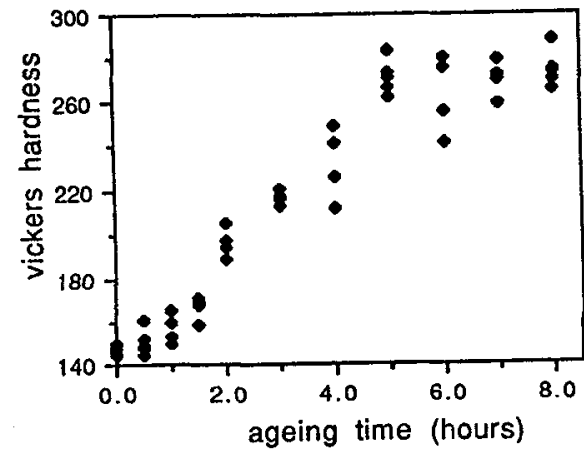

a)

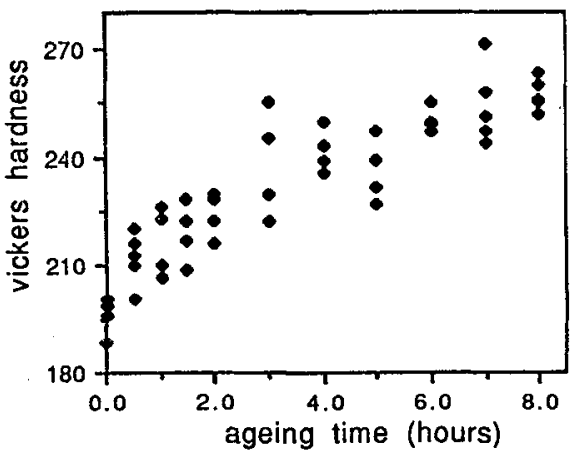

b)

Figure 5: Variation of the Vickers microhardness of a) Alloy 1 and b) Alloy 2 with the isothermal ageing time at $200^{\circ} \mathrm{C}$. 
As a result, the formation of precipitates during the ageing leads to the important increases in hardness as well as a degradation of the shape memory capacity and a change in martensitic transformation temperatures. The shape memory life can be approximately predicted by the austenitic ageing kinetics. According to the metallographic examinations, it can be suggested that high shape memory capacity in $\mathrm{CuZnAl}$ alloys at the elevated temperatures can be achieved by increasing the $\mathrm{Al}$ content or lowering the $\mathrm{Zn}$ content.

\section{CONCLUSIONS}

It can be reached the following conclusions from the above mentioned discussions;

(1) The stabilization process of the quenched martensite is mainly due to atom re-ordering of the martensite lattice assisted by a pinning mechanism of quenched-in vacancy or vacancy clusters.

(2) The growth units of two or four plates constitute self-accommodating morphology whose junction planes with the matrix are the conventional habit planes. The lower symmetry of the martensite compared to $\beta$ leads to the formation the many differently oriented martensite variants within a single crystal or a grain of $\beta$.

(3) The formation of $\alpha$-precipitates in $\mathrm{CuZnAl}$ alloy with lower content of aluminum shows an important increase by the ageing time at $200^{\circ} \mathrm{C}$, and can change the transformation temperatures and shape memory capacity by the interaction with martensite interfaces during the transformation.

(4) The Vickers hardness shows a tendency to increase with ageing time at $200^{\circ} \mathrm{C}$. According to the increase of $\alpha$ formation and hardness, the shape memory life may be predicted by the ageing kinetics.

\section{References}

[1] Beuhler W. J., Gilfrich J. W. and Wiley R. C., J. Apply. Physics, 34 (1963) 1475-1477.

[2] Otsuka K. and Shimizu K., International Metals Rewievs, 31 (1986) 93-114.

[3] Miyazaki S. and Otsuka K., ISIJ International, 29 (1989) 353-377.

[4] Adıgüzel O., Mater. Res. Bull., 30 (1995) 755-760.

[5] Kayalı N., Çakmak S., Artunç E. and Adıgüzel O., Cycling Effects on Transformation Behaviour in Shape Memory CuZnAl Alloys, Proc. of ICOMAT-95, J. de Physique IV C8, 5 (1995) 895-900.

[6] Shuchuan C., Hsu T. Y., Fan Y. and Jihau Z., Stabilization of Martensite and Ordering of the Parent Phase in a CuZnAl Alloy, Proc. of ICOMAT-92, Monterey 20-24 July, USA, 1992, J. Perkins Ed., (Monterey Institute for Advanced Studies, 1993), pp. 599-604.

[7] Sugimoto S., Sakamoto H., Hara T. and Tsuchiya H., The Effect of Grain Constraint, Heat Treatment and Compositional Change on the Behaviour of Martensitic Transformations in Alloys with the Composition Near Cu13Al-4Ni-1Zn (mass\%), in ref. 5, pp.925-930.

[8] Scarsbrook G., Cook J. M. and Stobbs W. M., Metall. Trans. A, 15A (1984) 1977-1986.

[9] Kayalı N., Özgen S. and Adıgüzel O., Mater. Res. Bull,, 32 (1997) 569-578.

[10] Humbeeck J. V., Janssen J., Ngoie M. and Delaey L., Scripta Metall., 18 (1984) 893-898.

[11] Humbeeck J. V., Delaey L. and Roedolf D., Stabilization of Isothermally Transformed 18R CuAINi Martensite, Proc. of ICOMAT 86, Nara, Japan, 1986 (The Japan Institute of Metals, 1986) pp. 862-867.

[12] Chandrasekaran M., Cesari E. and Humbeeck J. V., Reverse Transformation of Aged Cu-Zn-Al Martensite the Mechanism of Stabilization, in ref. 6, pp. 575-580.

[13] Scarsbrook G., Cook J. and Stobbs W. M., Ageing Effects in CuZnA1 Alloys, Proc. of ICOMAT 82, Leuven 1982, J. de Physique, C4 Suppl. to 12 (1982) 703-708.

[14] Saburi T., Nenno S., Kato S. and Takata K., J. Less Com. Met., 50 (1976) 223-236.

[15] Saburi T. and Wayman C. M., Acta Metall., 27 (1979) 979-995.

[16] Khan A. Q., J. Mater. Sci., 9 (1974) 1290-1296.

[17] Seguí C. and Cesari E., Characteristics of Martensite Stabilization in a High Temperature Cu-Zn-Al Alloy, in ref. 5, pp. 835-840.

[18] Spielfeld J. and Hornbogen E., The Influence of Dislocation Arrangements in Austenite on the Course of Diffusionless Transformation in Cu-Based Shape Memory Alloys, in ref. 5, pp. 817-822.

[19] Leu S. S. and Hu C. T., Effect of Aluminum Content on Precipitation in Cu-Zn-Al Shape Memory Alloys, in ref. 6, pp. 593-598. 